Laser Chem., Vol. 16, pp. 255-264

Reprints available directly from the publisher

Photocopying permitted by license only
(C) 1996 OPA (Overseas Publishers Association) Amsterdam B.V. Published in The Netherlands by Harwood Academic Publishers GmbH

\title{
SELECTIVE IR LASER INDUCED ISOMERIZATION AND DISSOCIATION OF BIS (TRIFLUOROMETHYL) KETENE MOLECULES
}

\author{
V. B. LAPTEV, L. M. TUMANOVA and E. A. RYABOV \\ Institute of Spectroscopy, Russian Acad. Sci., 142092 \\ Troitzk, Moscow Reg., Russia
}

(Received 21 December, 1995)

\begin{abstract}
Multiphoton IR laser induced isomerization and dissociation of $\left(\mathrm{CF}_{3}\right)_{2} \mathrm{C}=\mathrm{C}=\mathrm{O}(\mathrm{FMK})$ molecules have been studied. The antisymmetric stretch $\mathrm{v}_{1}=2192 \mathrm{~cm}^{-1}$ of $\mathrm{C}=\mathrm{C}=\mathrm{O}$ - and antisymmetric $\mathrm{v}_{16}=991$ $\mathrm{cm}^{-1}$ of $\mathrm{C}-\mathrm{C}-$ bonds were excited by the second- and first harmonics of a pulsed TEA $\mathrm{CO}_{2}$ laser. The dependence of isomerization conversion on laser radiation frequency, fluence, and number of shots was measured. The isomerization channel was predominant compared with dissociation for the conditions of IR multiphoton excitation under study.

The isomerization of FMK by the second-harmonic radiation of a $\mathrm{CO}_{2}$ laser was proved to be selective with respect to oxygen isotopes. The isomerization product (FMA molecules) was enriched with ${ }^{18} \mathrm{O}$ with maximum value of selectivity $\alpha(18 / 16)=3.9$ when FMK molecules were excited at $2 \omega_{\text {las }}=2143.8 \mathrm{~cm}^{-1}$.
\end{abstract}

KEY WORDS: Isotopically selective isomerization, dissociation, $\mathrm{CO}_{2}$ laser, second harmonic.

\section{INTRODUCTION}

The effect of vibrational multiphoton excitation and dissociation (MPD) of polyatomic molecules by powerful IR laser radiation has been under intense studies in many laboratories of the world since the early seventies and remains under investigation now as regards photochemical processes and its potential applications-laser chemical synthesis, isotope separation, etc. ${ }^{1,2}$ Less attention has been given to isomeric transformations resulting from MP excitation. At the same time, it has been pointed out that in practical applications molecular isomerization has a number of advantages over MPD, such as the formation of a stable molecule as a product rather than reactive radicals and, secondly, a lower reaction barrier. ${ }^{1,2}$

In our opinion, MP isomerization is of much interest since it gives an opportunity of directed production of the only reaction product, an isomer, as the laser radiation fluence and (or) frequency vary, as well as an opportunity to change the isotopic composition of the products. ${ }^{1,2} \mathrm{In}^{3}{ }^{3}$ for example, as cyclopropane molecules were excited by an optical parametric oscillator with a wavelength $3.22 \mu \mathrm{m}$, only isomerization was observed and the only reaction product was propylene. On the other hand, the final products consisted of equal quantities of the isomer and various 
dissociation products, when $9.50 \mu \mathrm{m}$ radiation of TEA $\mathrm{CO}_{2}$ laser was used. The isomerization of hexafluorocyclobutene selective with respect to carbon isotopes was reported by the authors of. ${ }^{4}$ The opportunity for isotopically $\left({ }^{14} \mathrm{~N} /{ }^{15} \mathrm{~N}\right)$ selective isomerization of methyl- and ethylisocyanide molecules was demonstrated in. ${ }^{5}$ To the best of our knowledge these works were the first attempts to realize isotopically selective isomerization of molecules under MP excitation. The above advantages of MP isomerization over MPD in practical applications, we believe, give a reason for further research in this direction.

This work is concerned with investigation of isomerization and dissociation processes of bis (trifluoromethyl) ketene molecules $(\mathrm{FMK})\left(\mathrm{CF}_{3}\right)_{2} \mathrm{C}=\mathrm{C}=\mathrm{O}$ during their MP excitation by the first- and second harmonics of pulsed radiation from a TEA $\mathrm{CO}_{2}$ laser. Besides, the problem of realization of oxygen isotope selectivity was put as the molecules are excited via the vibration of the $\mathrm{C}=\mathrm{O}$ bond, where a large isotopic shift was expected. ${ }^{2}$

\section{EXPERIMENTAL}

The initial FMK was kindly provided by Scientific Industrial Association P\&M. The analysis of the IR absorption spectrum of FMK (Fig. 1) shows a good agreement with the reference spectrum in ${ }^{6}$ as well as the absence of any impurities at a

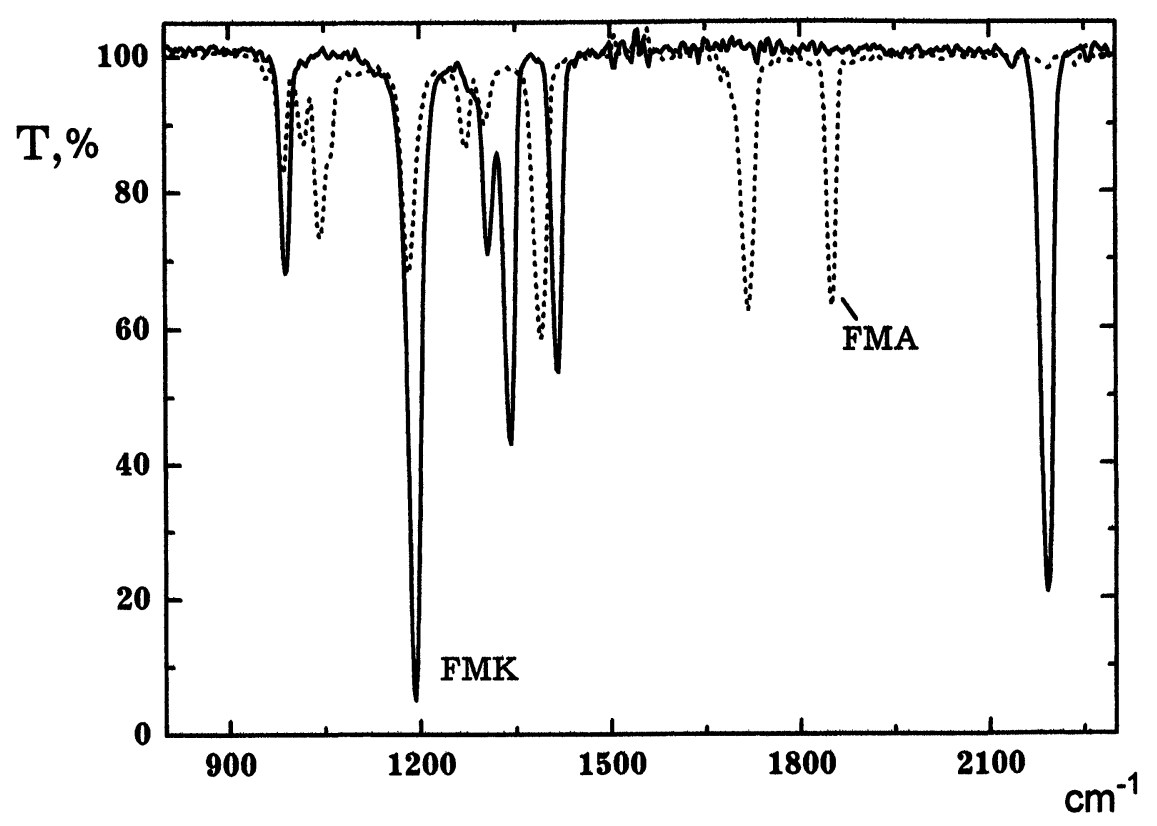

Figure 1 Infrared spectra of $\left(\mathrm{CF}_{3}\right)_{2} \mathrm{C}=\mathrm{C}=\mathrm{O}-\mathrm{FMK}$ (solid line) and $\mathrm{CF}_{2}=\mathrm{C}\left(\mathrm{CF}_{3}\right) \mathrm{COF}$-FMA (dotted line). Gas pressures -0.85 Torr FMK and 0.58 Torr FMA in 10-cm cell. 
level $<1 \%$. In the range from 5 to $10 \mu \mathrm{m}$ FMK has rather intense IR absorption bands $\left(\mathrm{v}_{1}=2192 \mathrm{~cm}^{-1}\right.$ and $\left.\mathrm{v}_{16}=988 \mathrm{~cm}^{-1}\right)$ assigned to antisymmetric stretching vibrations of bonds $\mathrm{C}=\mathrm{C}=\mathrm{O}$ and $\mathrm{C}-\mathrm{C}{ }^{6}{ }^{6}$ The FMK molecules were excited in two ways. In the first case the $\mathrm{CO}_{2}$ laser frequency $\omega_{\text {las }}=983.25 \mathrm{~cm}^{-1}$ (10R32 line) was nearly at resonance with the band $v_{16}=988 \mathrm{~cm}^{-1}$. In the second case FMK was excited by the second harmonic of a TEA $\mathrm{CO}_{2}$ laser with the frequency $2 \omega_{\text {las }}=2175.5 \div 2143.8 \mathrm{~cm}^{-1}(2 \cdot 9 \mathrm{R} 32 \div 2 \cdot 9 \mathrm{R} 10)$ that fell on the long-wave wing of the band $\mathrm{v}_{1}=2192 \mathrm{~cm}^{-1}$. The nonlinear single crystal $\mathrm{AgGaSe}_{2}{ }^{7}$ was used for efficient frequency doubling.

The TEA $\mathrm{CO}_{2}$ laser operated on the mixture $\mathrm{CO}_{2}: \mathrm{N}_{2}: \mathrm{He}=1: 0.2: 4$. The temporal shape of radiation pulse was standard-a front peak with FWHM of $\sim 80$ ns containing $\sim 70 \%$ of the total pulse energy and a "tail" with its full width of about $1.5 \mu$ s. The TEA $\mathrm{CO}_{2}$ laser radiation was focused by lenses with $\mathrm{f}=80 \div 200 \mathrm{~cm}$ and directed into stainless steel cells with $\mathrm{NaCl}$ windows, 100 and $112 \mathrm{~mm}$ long and 24 and $14 \mathrm{~mm}$ in diameter, respectively. The second-harmonic radiation was focused by lenses with $\mathrm{f}=8$ and $20 \mathrm{~cm}$, the ratio of the fluence in the focus of the lens to that at the inlet of the cell being $\sim 10$ and $\sim 1.5$, respectively. The radiation fluence in the short-focus lens caustic was usually $2 \div 3 \mathrm{~J} / \mathrm{cm}^{2}$ and in the caustic of the lens with $\mathrm{f}=20 \mathrm{~cm} 0.5 \div 0.7 \mathrm{~J} / \mathrm{cm}^{2}$. The IR absorption spectra of FMK and photochemical reaction products were recorded with an IR spectrophotometer (SPECORD-M82). The conversion of FMK molecules was determined from the consumption which, in its turn, was calculated from the IR spectra before and after irradiation. After irradiation, when necessary, the remaining FMK was separated from the resultant isomer (pentafluoromethacrylyl fluoride, $\mathrm{F}_{2} \mathrm{C}=\mathrm{C}\left(\mathrm{CF}_{3}\right) \mathrm{COF}-\mathrm{FMA}$ ) through lowtemperature distillation. The purity of the separated compounds was controlled by IR spectra. The IR spectrum of FMA (Fig. 1.) was compared with those known from references. ${ }^{8,9}$ Due to a large difference in boiling temperature between FMK and FMA (5 and $52^{\circ} \mathrm{C}$, accordingly ${ }^{8}$ ) the content of residual FMK in FMA and vice versa did not usually exceed $5 \%$. It should be noted, that FMK and the products of its isomerization and dissociation are stable in a gas phase. After keeping the irradiated FMK and its products in the cell for 24 hours we have not found any appreciable changes in the IR spectra.

Isotopic analysis of irradiated FMK and its isomer as well as the detection of the dissociation product $\mathrm{CO}$ were performed with a mass spectrometer (MI 1309). The content of oxygen isotopes in FMK and FMA was calculated from the intensities of the mass-peaks with $\mathrm{m} / \mathrm{e}=159$ and 161 which corresponded to the ions $\mathrm{C}_{4} \mathrm{~F}_{5}{ }^{16} \mathrm{O}^{+}$and $\mathrm{C}_{4} \mathrm{~F}_{5}{ }^{18} \mathrm{O}^{+}$, respectively. The enrichment factor with respect to ${ }^{16} \mathrm{O}$ - or ${ }^{18} \mathrm{O}$ - isotopes in FMK and FMA and isotopic selectivity were estimated using the formulas taken from. ${ }^{1}$ The selectivity was defined as a ratio of isomerization yields of molecules with ${ }^{16} \mathrm{O}$ and ${ }^{18} \mathrm{O} \alpha(18 / 16)=\beta_{18} / \beta_{16}$ or $\alpha(16 / 18)=\beta_{16} / \beta_{18}$. The dissociation product $C O$ was detected using a mass spectrometer via the peaks with $\mathrm{m} / \mathrm{e}=28,29,30$. Before analysis $\mathrm{CO}$ was separated from FMK and the rest of the products by freezing them at $-196^{\circ} \mathrm{C}$. All the experiments were carried out at a constant pressure of FMK (0.85 Torr). This pressure ensures near-collisionless conditions of FMK MP excitation by a laser pulse with duration of about $80 \mathrm{~ns}^{1}$ 


\section{RESULTS AND DISCUSSION}

The first experiments revealed a considerable difference in the products of photochemical reactions as a result of irradiation of FMK at the frequencies $2 \omega_{\text {las }}=2171.5 \div 2143.8 \mathrm{~cm}^{-1}$ and $\omega_{\text {las }}=983.25 \mathrm{~cm}^{-1}$. In the first case we could only observe isomerization of FMK to FMA. At the same time, small amounts of CO were detected by a mass spectrometer. The latter is an indication of some dissociation of FMK molecules. According to our estimations, however, the contribution of dissociation to the whole conversion of FMK was insignificant $(<1 \%)$, despite rather a high fluence of the second-harmonic radiation $\left(2 \div 3 \mathrm{~J} / \mathrm{cm}^{2}\right)$. In the second case a set of products was essentially different. The characteristic bands in the IR absorption spectrum allowed us to conclude that, besides the isomer, $\mathrm{C}_{3} \mathrm{~F}_{6}, \mathrm{C}_{2} \mathrm{~F}_{4}$, $\mathrm{COF}_{2}$ as well as an unidentified product, with its band at the frequency of $2052 \mathrm{~cm}^{-1}$, were formed. Also, CO was recorded by mass spectrometry. Figure 2 shows the kinetics of accumulation of some of the listed products with an increase in the number of laser pulses $\left(\omega_{\text {las }}=983.25 \mathrm{~cm}^{-1}\right)$. It may be seen that the formation of $\mathrm{C}_{3} \mathrm{~F}_{6}$ and the product with band $2052 \mathrm{~cm}^{-1}$ increase with irradiation. At the same time, the amount of FMA increases only at the starting of irradiation and then begins to drop. Such behaviour can be attributed to the dissociation of the accumulating isomer. This is possible, since the frequency of exciting radiation $\omega_{\text {las }}=983.25 \mathrm{~cm}^{-1}$ is at resonance with the IR band of the isomer at $986 \mathrm{~cm}^{-1}$ (see Fig. 1). Indeed, as the pure isomer was irradiated at $\omega_{\text {las }}=983.25 \mathrm{~cm}^{-1}$, its dissociation was observed and the qualitative and quantitative composition of the products was the same as in the case of FMK.

To understand what products are formed as a result of dissociation of FMK itself we recorded them after irradiation of the sample by a single laser pulse. The basic products of $\mathrm{FMK}$ dissociation were $\mathrm{C}_{3} \mathrm{~F}_{6}$ and $\mathrm{CO}$, which agrees with the results of the experiments on UV photolysis of unfluorinated dimethylketene, $\left(\mathrm{CH}_{3}\right)_{2} \mathrm{C}=\mathrm{C}=\mathrm{O} .{ }^{10}$ The quantitative and qualitative composition of the products, resulting from MP excitation of FMK, depends on the excitation level which is determined, in turn, by laser radiation fluence. With $\omega_{\text {las }}=983.25 \mathrm{~cm}^{-1}$ and $\Phi<1 \mathrm{~J} / \mathrm{cm}^{2}$, for example, the only product of reaction observed is the isomer FMA. The absence of other products was confirmed by both IR and mass spectra. As the fluence exceeds $1 \mathrm{~J} / \mathrm{cm}^{2}, \mathrm{C}_{3} \mathrm{~F}_{6}$ and $\mathrm{CO}$ - dissociation products of $\mathrm{FMK}$ begin to appear.

Table 1 presents the fractions of the isomer and the dissociation product $\mathrm{C}_{3} \mathrm{~F}_{6}$ for two fluence values. It can be seen that with a small excess $\left(\Phi=1.3 \mathrm{~J} / \mathrm{cm}^{2}\right)$ over the

Table 1 The ratio of isomerization and dissociation yields for different levels of MP excitation of FMK molecules, $\omega_{\text {las }}=983.25 \mathrm{~cm}^{-1}$.

\begin{tabular}{lrc}
\hline$\Phi, \mathrm{J} / \mathrm{cm}^{2}$ & 1.3 & 3.4 \\
Isomer yield, \% & 95 & 58 \\
$\mathrm{C}_{3} \mathrm{~F}_{6}$ yield, \% & 5 & 42 \\
Average absorbed energy, $\mathrm{kcal} / \mathrm{mol}$ & 103 & 210 \\
\hline
\end{tabular}




\section{$\mathrm{p}_{\text {FMA }}$,}

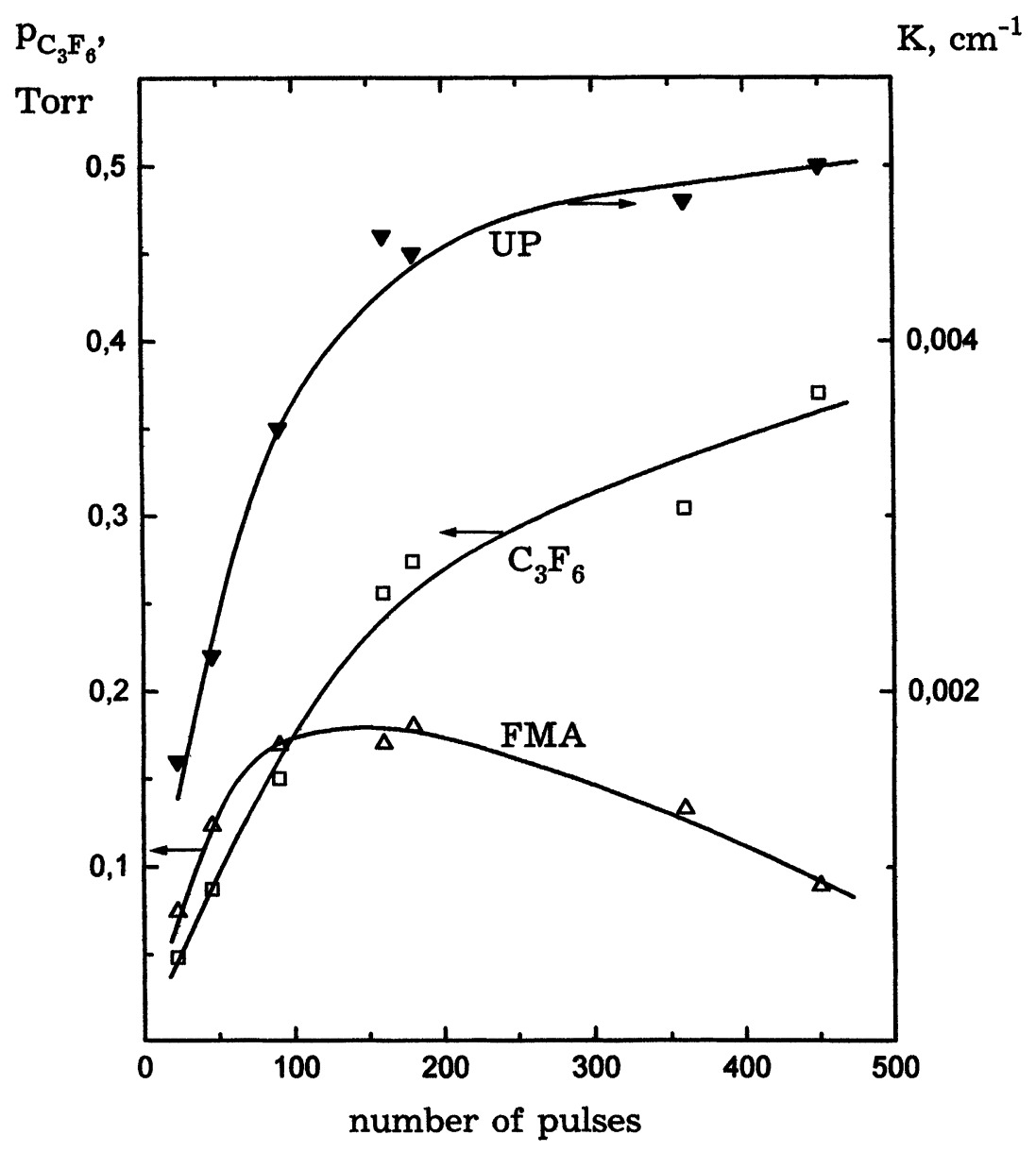

Figure 2 Dependence of amount of product on the number of laser pulses; $\omega_{\text {las }}=983.25 \mathrm{~cm}^{-1}$, $\Phi=2.6 \mathrm{~J} / \mathrm{cm}^{2}$; UP-unidentified product with IR absorption band at $2052 \mathrm{~cm}^{-1}$, the amount of UP is expressed through absorption factor $\mathrm{K}$.

threshold fluence $\left(\Phi \approx 1 \mathrm{~J} / \mathrm{cm}^{2}\right)$, the main reaction product is FMA and the percentage of dissociation products is insignificant (about $5 \%$ ). As the fluence increases up to $3.4 \mathrm{~J} / \mathrm{cm}^{2}$, the share of dissociation products increases but isomerization dominates $(58 \%)$ over dissociation as before. The presence of such a phototransformation channel as isomerization, which is the main one under the conditions of our experiments, makes the pulsed IR photolysis of FMK quite different compared with UV photolysis of dimethylketene $\left(\mathrm{CH}_{3}\right)_{2} \mathrm{C}=\mathrm{C}=\mathrm{O} .{ }^{10}$ To relate the fluence of exciting radiation to the average excitation level of FMK molecules we measured the energy absorbed per molecule $\left(\mathrm{E}_{\mathrm{abs}}\right)$ as a function of fluence (see Fig. 3). Since with $\Phi>1 \mathrm{~J} / \mathrm{cm}^{2}$ the conversion of initial FMK to its products is close to $100 \%$, it is 


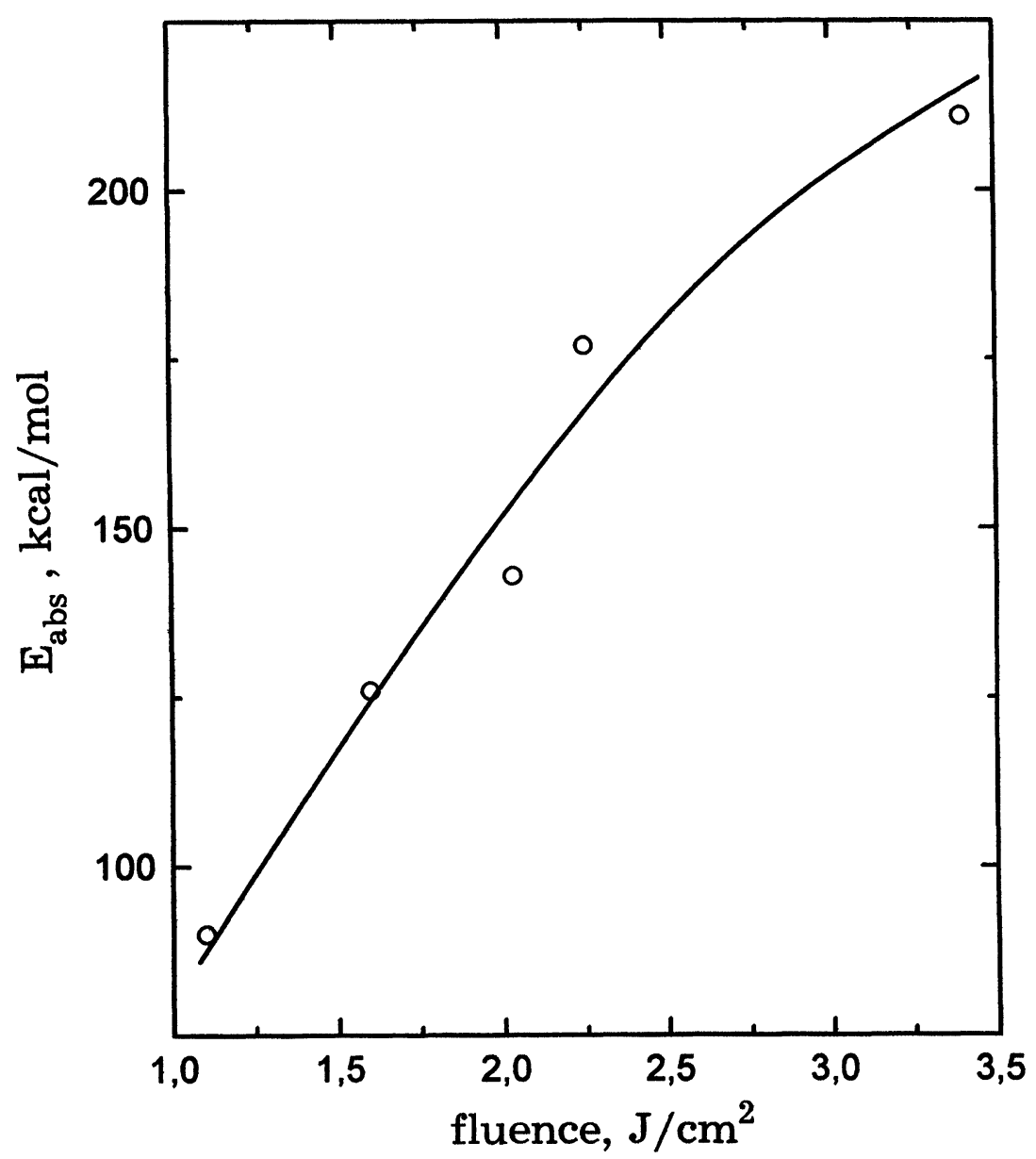

Figure 3 The energy absorbed per FMK molecule $\left(\mathrm{E}_{\mathrm{abs}}\right)$ as a function of laser radiation fluence; $\omega_{\text {las }}=983.25 \mathrm{~cm}^{-1}$.

possible to consider, that all the molecules in the volume under irradiation interact with the field. Therefore, the average excitation level measured really corresponds to the average energy of the ensemble of excited molecules.

We shall note two important items. First, with $\Phi>1 \mathrm{~J} / \mathrm{cm}^{2}\left(\omega_{\text {las }}=983.25 \mathrm{~cm}^{-1}\right)$ the average excitation level of FMK molecules exceeds, and sometimes considerably, the energy of cleavage of the weakest bond $\mathrm{C}=\mathrm{C}(\sim 80 \mathrm{kcal} / \mathrm{mol}) .{ }^{11} \mathrm{MP}$ absorption of excess energy, sometimes exceeding the dissociation energy by several times, quite often takes place for MP excitation of polyatomic molecules with the number of atoms $\mathrm{n}>10\left(\mathrm{see}^{12}\right.$ and $\left.^{13,14}\right)$. Using the semiclassical approximation of RRKM theory, similarly to, ${ }^{12}$ we estimated the level of excitation of the 11-atom FMK molecule for typical values of excitation rate in a quasi-continuum $\left(\sim 10^{9} \mathrm{~s}^{-1}\right)$ and frequency factor $\left(\sim 10^{13} \mathrm{~s}^{-1}\right)$. The vibrational energy absorbed by FMK from the IR 
field was found to be $\sim 260 \mathrm{kcal} / \mathrm{mol}$ which is in qualitative agreement with Figure 3. The second important point is also related to the features of excitation of polyatomic molecules with $n>10$. For example, with the average absorbed energy $\mathrm{E} \approx 90 \mathrm{kcal} / \mathrm{mol}$ exceeding the cleavage energy of the $\mathrm{C}=\mathrm{C}$ bond, the contribution of dissociation to the entire conversion of FMK is not high $(\sim 5 \%)$ and the isomerization channel dominates over the dissociation channel. This is conditioned by the small value of the unimolecular dissociation rate compared with the rate of isomerization at a given excitation level because of a higher activation energy barrier for dissociation. As the internal vibrational energy of the molecules increases up to $\sim 200 \mathrm{kcal} / \mathrm{mol}$, the unimolecular decay rate rises rapidly and the contributions of the dissociation and isomerization channels become almost the same.

The data in Table 1 allows us to estimate the minimal difference $\Delta \mathrm{E}$ between the energies of FMK dissociation and isomerization. This can be done with the use of the semiclassical approximation of RRKM theory. Under the corresponding assumption, as in, ${ }^{12}$ the expression for the rate constant $\left(\mathrm{k}_{\mathrm{uni}}\right)$ of the unimolecular reaction is:

$$
\mathrm{k}_{\mathrm{uni}}=\bar{\omega}\left[1-\mathrm{D} /\left(\mathrm{E}+\mathrm{E}_{0}\right)\right]^{\mathrm{s}-1}
$$

where $\bar{\omega}$ is the frequency factor; $\mathrm{D}=80 \mathrm{kcal} / \mathrm{mol}$ is the dissociation energy; $\mathrm{E}$ is the vibrational energy accumulated in a molecule; $\mathrm{E}_{0}$ is the zero-point vibrational energy of the molecule; $s=27$ is the number of vibrational degrees of freedom of an 11 -atom molecule. Now we shall make the following assumptions. Let the isomerization and dissociation yields $\beta_{\text {iso }}$ and $\beta_{\text {diss }}$ be proportional to the corresponding rate constants of unimolecular reaction and, hence, the ratio of the isomerization yield to the dissociation yield be equal to the ratio of the rate constants. Then, assume that the frequency factors for the isomerization and dissociation reactors are equal, i.e. $\bar{\omega}_{\text {iso }}=\bar{\omega}_{\text {diss. }}$ In this case we get the following expression:

$$
\Delta \mathrm{E}=\left[\left(\beta_{\text {iso }} / \beta_{\text {diss }}\right)^{1 /(s-1)}-1\right]\left(\mathrm{E}+\mathrm{E}_{0}-\mathrm{D}\right)
$$

The value of $E_{0}$ estimated from the data obtained $\mathrm{in}^{6}$ is $\sim 26 \mathrm{kcal} / \mathrm{mol}$. The substitution of the values of $\beta_{\text {iso }}, \beta_{\text {diss }}$ and $E$ from Table 1 and $E_{0}$ and $D$ into the formula gives $\Delta \mathrm{E}=2 \div 6 \mathrm{kcal} / \mathrm{mol}$. The first assumption is valid and semiclassical approximation of RRKM theory can be used when the isomerization is irreversible. The latter is supported by experimental observation of $\sim 100 \%$ isomeric conversion. At the same time, it should be kept in mind that barrier reactions, isomerization being one of them, are usually characterized by lower frequency factors as compared to dissociation reactions, ${ }^{15} \bar{\omega}_{\text {iso }}<\bar{\omega}_{\text {diss. }}$. Thus, $\Delta \mathrm{E}=2 \div 6 \mathrm{kcal} /$ mol is a minimal value of the difference in energies between isomerization and dissociation channels.

As noted above, only one product of photochemical reaction (FMA) was detected in the IR absorption spectrum as FMK was excited by second-harmonic radiation at $2 \omega_{\text {las }}=2171.5 \div 2143.8 \mathrm{~cm}^{-1}$. The average absorbed energy measured with $\Phi_{2 \omega}=0.7 \mathrm{~J} / \mathrm{cm}^{2}$ was $\sim 40 \mathrm{kcal} / \mathrm{mol}$. Therefore, with $\Phi_{2 \omega}=2 \div 3 \mathrm{~J} / \mathrm{cm}^{2}$ FMK molecules are expected to be excited to higher vibrational states. Nevertheless, there is no 
marked dissociation of FMK observed. The dependence of the average excitation level on the first-harmonic radiation fluence $\mathrm{E}(\Phi)$ (see Fig. 3) makes it possible to evaluate the level of energy when the contribution of dissociation to the total conversion of FMK becomes appreciable $(>1 \%)$. This value comes to about $80 \mathrm{kcal} / \mathrm{mol}$. The absence of pronounced dissociation in case of FMK excitation by the second harmonic shows that the average excitation level of molecules is less than $80 \mathrm{kcal} / \mathrm{mol}$. This fact indicates that the dependence $\mathrm{E}(\Phi)$ is less steep for the second harmonic which is not surprising because the excitation conditions for the first and second harmonics differ greatly.

As pointed out above, MP excitation of 0.85 Torr FMK by a pulse with its duration of $\sim 80 \mathrm{~ns}$ occurs practically in collisionless conditions. However, all subsequent chemical reactions of isomerization and dissociation proceed in the presence of collisions. This is because of the long lifetime of vibrationally highly-excited FMK molecules. The reaction rate constant of unimolecular reaction estimated in a semiclassical approximation of RRKM theory for molecules with their vibrational energy of $130 \mathrm{kcal} / \mathrm{mol}$ comes to $160 \mathrm{~s}^{-1}$, i.e. the lifetime of excited molecules is about $6 \mathrm{~ms}$. Since the fraction of excited molecules approaches $100 \%$ in the volume under irradiation, they are not be able to be deactivated and therewith stabilized in a certain isomeric form due to vibrational exchange. The role of V-T relaxation is insignificant because of high vibrational heat capacity of 11-atom molecules. Therefore, deactivation of excited molecules and their isomeric stabilization may only occur due to diffusion from the exposed volume into the cold part of the cell where they relax when colliding with unexcited molecules. The diffusion time estimated in our experiments was several milliseconds.

The isomerization of FMK in case of MP excitation at the frequency $2 \omega_{\text {las }}=2171.5 \div 2143.8 \mathrm{~cm}^{-1}$ was found to be selective with respect to the oxygen isotopes ${ }^{16} \mathrm{O}$ and ${ }^{18} \mathrm{O}$. The isotopic selectivity of isomerization was calculated from the variation of the isotopic ratio in FMK and the isomer separated from each other. Figure 4 shows the selectivity as a function of laser radiation frequency. It can be seen that as the frequency decreases, the isomerization selectivity of FMK molecules with ${ }^{16} \mathrm{O}$ drops and, starting with $2 \omega_{\text {las }} \approx 2153 \mathrm{~cm}^{-1}$, the molecules with $\mathrm{O}^{18}$ are mainly isomerized. The maximum selectivity values with respect to ${ }^{16} \mathrm{O}$ or ${ }^{18} \mathrm{O}$ measured in our experiments come to 4.2 and 3.9 , respectively.

In spite of a considerable detuning of the laser radiation (up to $48 \mathrm{~cm}^{-1}$ ) from the center of the linear IR absorption band $\left(\mathrm{v}_{1}=2192 \mathrm{~cm}^{-1}\right)$ of molecules with the basic isotope ${ }^{16} \mathrm{O}$, the values obtained for selectivity with respect to ${ }^{18} \mathrm{O}$ are comparatively low $-\alpha(18 / 16)=3.9$. In our opinion, it may be caused by the following factors. First, with detuning below $2150 \mathrm{~cm}^{-1}$ the laser radiation frequency is at resonance with the IR combination mode of the molecules with the isotope ${ }^{16} \mathrm{O}$ $\mathrm{v}_{2}+\mathrm{v}_{18}=2136 \mathrm{~cm}^{-1}{ }^{6}$ This band, when excited, can contribute to the isomerization yield and therby reduce the selectivity. Second, primary (spectral) selectivity of MP excitation can be reduced by interisotopic vibrational exchange ${ }^{1}$ since under the conditions of our experiment, as it was shown above, the FMK molecules are in highly-excited states for a long time and are deactivated due to the diffusion from the exposed volume into the cold area in times of around several milliseconds. 


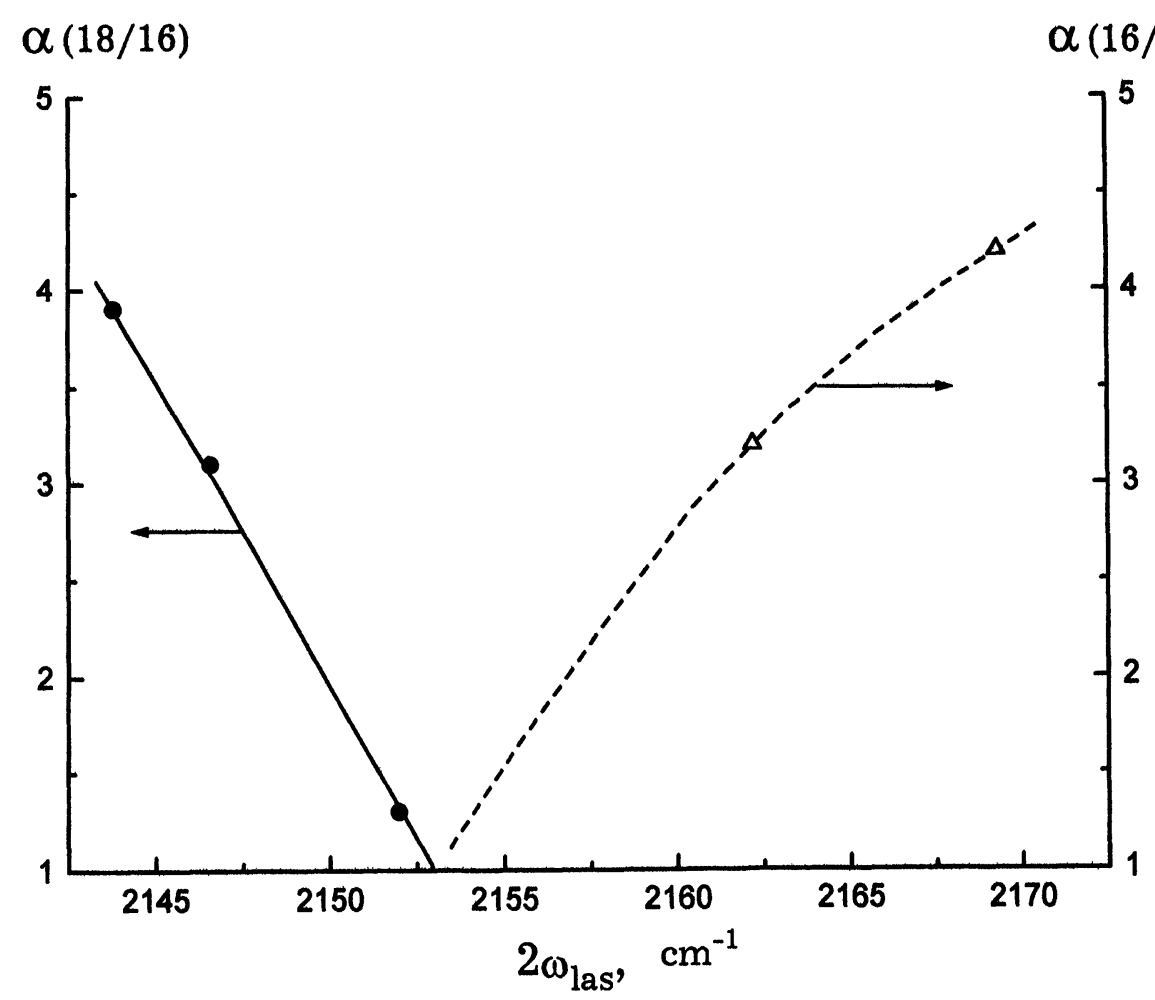

Figure 4 Dependence of selectivity of IR multiphoton isomerization of FMK molecules on $2 \omega_{\text {las }}$ laser radiation frequency; $\alpha(16 / 18)$ - dotted line and $\alpha(18 / 16)$-solid line.

\section{CONCLUSION}

1. The main channel of phototransformation of bis (trifluoromethyl) ketene molecules following IR MP excitation is isomerization into pentafluoromethacrylyl fluoride.

2. The contribution of dissociation becomes comparable to isomerization only at high levels of vibrational excitation of FMK molecules (more than $200 \mathrm{kcal} /$ mol).

3. The isomerization of FMK by the second-harmonic radiation of a pulsed TEA $\mathrm{CO}_{2}$ laser was found to be selective with respect to oxygen isotopes. The maximum value of selectivity with respect to ${ }^{16} \mathrm{O}$ or ${ }^{18} \mathrm{O}$ come to 4.2 or 3.9 , respectively.

\section{Acknowledgement}

This work was supported in part by a Conversion Grant Program of the International Science and Technology Center (Project No 012-94). 


\section{References}

1. V. N. Bagrataschvili, V. S. Letokhov, A. A. Makarov and E. A. Ryabov, Multiple Photon Infrared Laser Photophysics and Photochemistry (Harwood Acad. Publishers, Chur, London-Paris-New York, 1985), pp.366-376.

2. Yu. N. Molin, V. N. Panfilov and A. K. Petrov, Infrared Photochemistry (Novosibirsk, SO, Nauka, 1985), Chap. 7 (in Russian).

3. R. B. Hall and A. Kaldor, J. Chem. Phys., 704027 (1979).

4. A. Yogev and R. M. J. Benmair, Chem. Phys. Lett., 63558 (1979).

5. A. Hartford Jr and S. A. Tuccio, Chem. Phys. Lett., 60431 (1979).

6. F. A. Miller and F. E. Kiviat, Spectrochimica Acta, 25A 1577 (1969).

7. V. V. Badikov, V. B. Laptev and V. P. Paniutin et al., Sov. J. Quant. Electr., 22722 (1992).

8. D. C. England and C. G. Krespan, J. Am. Chem. Soc., 885582 (1966).

9. Sh. Nadzhimutdinov, N. A. Slovokhotova and V. A. Kargin, Russ. J. Phys. Chem., 40893 (1966).

10. J. G. Calver, Ja. and N. Pitts, Jr., Photochemistry (John Willey \& Sons, Inc., New York-London, 1996).

11. L. V. Gurvich, G. V. Karachentsev and V. N. Kondrat'ev et al., Energies of chemical bonds cleavage (Moscow, Nauka, 1974), p. 70, (in Russian).

12. V. N. Bagrataschvili, S. I. Ionov, M. B. Kuz'min and V. S. Letokhov, Sov. Phys. JETP, 63453 (1986).

13. V. B. Laptev, E. A. Ryabov and L. M. Tumanova, Sov. J. Quant. Electr., 19827 (1989).

14. V. B. Laptev, L. M. Tumanova and E. A. Ryabov, Chem. Phys. Rep., 135568 (1994).

15. P. J. Robinson and K. A. Holbrook, Unimolecular Reactions (Wiley-Interscience, London-New York-Sydney-Toronto, 1972). 